\title{
LESBIANIDADES E LEI MARIA DA PENHA: PROBLEMATIZAÇÕES A PARTIR DE UMA ANÁLISE JURISPRUDENCIAL NOS TRIBUNAIS DO SUL DO PAÍS
}

\author{
Thaís da Silva Durães ${ }^{1}$ \\ Isadora Vier Machado ${ }^{2}$
}

RESUMO: Ao se estabelecer em torno da categoria gênero, a Lei 11.340/06 buscou contemplar as diversas emanações de violências dirigidas contra as mulheres, em episódios domésticos e familiares, inclusive em contextos de lesbianidades, nos quais, necessariamente, uma mulher encontrese no polo ativo do conflito, como dispõe o artigo $5^{\circ}$, parágrafo único da Lei. $\mathrm{O}$ Judiciário apresenta papel fundamental na implementação da Lei Maria da Penha e, em específico, no âmbito das lesbianidades, dada a condição de invisibilidade que estas relações vivenciam. Assim, analisou-se como os Tribunais de Justiça do Sul se posicionam quanto à incidência da Lei nesses casos, principalmente quanto a leitura que as (os) julgadoras (es) realizam quando o sujeito da violência doméstica seja uma mulher.
Palavras-chave: Lei Maria da Penha. Lesbianidades. Violência doméstica.

\begin{abstract}
Through gender category, Law 11.340/06 sought to contemplate the several emanations of violence against women in domestic and family episodes, including lesbian contexts in which, necessarily, a woman lie on the active pole of the conflict, as provided by its article 5 , paragraph. The judiciary has a key role in the implementation of the Maria da Penha Law and, in particular, within the lesbian conflicts, given the condition of invisibility that these relationships experience. Thus, the aim of this article was to examined how the Southern Courts of Justice are positioned on the incidence of Law in such cases, especially when the author of domestic violence is a woman.
\end{abstract}

\footnotetext{
${ }^{1}$ Graduada pela Universidade Estadual de Maringá. Artigo vinculado ao Projeto de Pesquisa institucional “A Implementação da Lei 11.340/06 (Lei Maria da Penha) sob a perspectiva de gênero e a visão dos tribunais pátrios".

${ }^{2}$ Doutora em Ciências Humanas pela UFSC (2010). Professora Adjunta de Direito Penal da Universidade Estadual de Maringá.
} 
Keywords: Maria da Penha Law. Lesbianities. Domestic violence.

\section{INTRODUÇÃO}

Sancionada em 7 de agosto de 2006, a Lei 11.340, conhecida como Lei Maria da Penha, ingressou no cenário político pátrio imbuída de significativa carga histórica no contexto de enfrentamento à violência contra as mulheres no Brasil. Contando com mecanismos que visam prevenir e coibir as violências, segundo dado apresentado pela Secretaria de Políticas para Mulheres $^{3}$, até 2011, contabilizou-se a expedição de, aproximadamente, 281.302 medidas protetivas ${ }^{4}$ desde o surgimento da Lei, estimando-se que, até 2012, este número tenha ultrapassado o marco de 350 mil, o que demonstra considerável utilização de suas políticas pelas instâncias do Judiciário.

A nova Lei constitui-se como exemplar conquista dos movimentos feministas que, desde meados dos anos 70 (Soares e Sardenberg, 2011: 1), buscam dar visibilidade à violência perpetrada contra as mulheres. Os feminismos assumiram papel de destaque no processo de desocultação da violência e de politização dos espaços privados (domésticos), principalmente por revelar as múltiplas formas de violência sofridas pelas mulheres, captando-as em suas variadas dimensões. De modo que, segundo Vera Regina Pereira de Andrade:

\begin{abstract}
Está subjacente a postular o deslocamento da gestão da violência do espaço tradicionalmente definido como privado (a domesticidade familiar) para o espaço definido como público (e estatal); o deslocamento do controle informal materializado na família para o controle social formal materializado no sistema penal (Andrade, 2003: 115).
\end{abstract}

Em sua redação, a Lei delimita requisitos de incidência, fixando, no

em risco iminente à sua integridade pessoal. A esse respeito, Nilo Batista aponta que: "Certamente o setor mais criativo e elogiável da lei reside nas medidas protetivas de urgência. Ali estão desenhadas diversas providências que podem, no mínimo, assegurar níveis suportáveis no encaminhamento de solução para conflitos domésticos e patrimoniais" (Batista, Nilo (2009), "Prefácio", in Mello, Adriana Ramos de (Org.), Comentários à Lei de violência doméstica e familiar contra a mulher, Rio de Janeiro: Lumen Juris.). 
caput de seu artigo 5', que: "para os efeitos desta Lei, configura violência doméstica e familiar contra a mulher qualquer ação ou omissão baseada no gênero que lhe cause morte, lesão, sofrimento físico, sexual ou psicológico e dano moral ou patrimonial" (grifou-se). Assim, de pronto se esclarece que o diploma se articula em torno da categoria gênero, cuja presença é fundamental para a incidência da Lei, excluindo-se, desta forma, as demais formas de violência que não se enquadrem neste núcleo.

Insta ressaltar que, dentre todas as inovações trazidas pela Lei, dá-se destaque ao contido no parágrafo único, do mesmo artigo $5^{\circ}$, que prevê: "As relações pessoais enunciadas neste artigo independem de orientação sexual" (grifou-se). Dessa forma, abre-se espaço para a aplicação dos mecanismos contidos na Lei em conflitos que envolvam mulheres, tanto no âmbito da unidade doméstica e familiar, quanto em qualquer relação íntima de afeto.

Resta, então, explorar como se dá a aplicação da Lei 11.340/06 pelos Tribunais nos conflitos entre mulheres, norteados pela orientação sexual do sujeito passivo, avaliando-se o senso das instâncias superiores na apreciação de tais casos e examinando de que forma a jurisprudência tem convergido com a proposta instituída pelo Legislativo, que buscou frisar a garantia de proteção às diversas emanações de violência dirigidas às mulheres, consideradas em sua individualidade, inclusive nos limites e manifestações de sua sexualidade.

Propõe-se, portanto, o presente trabalho, a analisar a aplicabilidade da Lei Maria da Penha, pelos tribunais do sul do país, em casos em que haja conflitos que envolvam mulheres, nos quais necessariamente seja uma delas a agressora, tendo-se como parâmetro expressa previsão contida no mesmo diploma, em seu artigo $5^{\circ}$, parágrafo único, ao dispor que as relações pessoais enunciadas independem de orientação sexual.

A metodologia utilizada compõese de pesquisa bibliográfica, contando com referências dos campos das Ciências Sociais e Direito, bem como pela análise jurisprudencial dos Tribunais de Justiça dos estados do Paraná, Santa Catarina e Rio Grande do Sul. Os Tribunais sulistas foram contemplados na pesquisa pelas seguintes razões: pelo dado apresentado na CPMI da violência doméstica e familiar que aponta o Paraná como 
terceiro estado em número de homicídios de mulheres ${ }^{5}$; pelo escasso número de precedentes jurisprudências no Tribunal de Santa Catarina a respeito da aplicação da Lei em conflitos envolvendo mulheres, e pelos resultados obtidos no estado do Rio Grande do Sul quanto à possibilidade de aplicação da Lei, principalmente, por apresentar decisões paradigmáticas em contexto de lesbianidades.

A pesquisa qualitativa (Gabardo e Morettini, 2013) foi realizada entre a data da sanção da Lei 11.340/06 a janeiro de 2017, alcançando-se o número de 56 acórdãos, os quais se encontram disponíveis nos sítios eletrônicos oficiais de cada Tribunal, distribuídos da seguinte forma: 34 oriundos do Tribunal de Justiça do Rio Grande do Sul, 18 do Paraná e 4 de Santa Catarina. Os parâmetros de buscas podem ser instituídos a partir de diversos critérios: nomes de julgador/as, período, terminologias. Dentre estes, o último foi escolhido, tendo a busca sido pautada pela combinação das seguintes categorias: Lei Maria da Penha + Orientação Sexual; Lei Maria da Penha

5 Senado Federal (2012), “CPMI Violência contra a Mulher". Página consultada a 07.11.2014,
+ Orientação Sexual + Agressora; Lei 11.340/06 + Mulher + Agressora; Lei Maria da Penha + Mulher + Polo Ativo; Violência Doméstica + Lei Maria da Penha + Mulher + Agressora; Lesão Corporal + Lei Maria da Penha + Mulher; Lei Maria da Penha + Mulher + Aplicação; Lei Maria da Penha + Agressora + Mulher; Lei Maria da Penha + Mulher + Ofendida; Lei Maria da Penha + Conflito entre mulheres; Lei Maria da Penha + Violência envolvendo Mulheres; Lei Maria da Penha + Aplicação contra Mulheres; Lei Maria da Penha + Homossexual; Lei Maria da Penha + Lésbicas; Violência Doméstica + Homossexual e Violência Doméstica + Lésbicas.

Ao longo da busca, foi possível notar uma pluralidade de julgados referindo conflitos entre mulheres, sob a incidência da Lei Maria da Penha. A princípio, objetivava-se a análise dos julgados relativos, exclusivamente, a contextos de lesbianidades. Entretanto, como estes foram pouco representativos numericamente, decidiu-se pela inclusão, na análise, de decisões que contemplassem outros subtipos de

http://www.senado.gov.br/atividade/comissoes/c omissao.asp?origem $=\mathrm{CN} \&$ com $=1580$. 
conflitos entre mulheres, por entender que o conteúdo destas também revelava dados importantes sobre a forma como os tribunais têm operado a Lei Maria da Penha em contextos de lesbianidades. Assim, as decisões foram agrupadas de acordo com as peculiaridades de cada caso envolvendo mulheres, resultando em 7 grupos, dentre os quais: 1. Decisões sobre relacionamentos afetivoconjugais; 2. Decisões sobre relação mãe-filha/madrasta-enteada; 3. Decisões sobre relação sogra-nora; 4. Decisões envolvendo irmãs; 5. Decisão sobre relação entre cunhadas; 6. Decisão envolvendo primas/tia e sobrinha; 7. Decisões diversas, que não se encaixaram nos demais agrupamentos.

Diante destes agrupamentos, buscou-se avaliar como a Lei foi aplicada a cada caso, especificamente levando-se em consideração qual entendimento de gênero os julgadores veiculam, quais as delimitações para a aplicação da Lei e critérios utilizados pelos magistrados, notadamente quando as mulheres, além de figurarem no polo passivo da situação de violência, também são sujeitos ativos de tais práticas.

\section{LESBIANIDADES: DA INVISIBILIDADE À PROTEÇÃO LEGAL}

Ao se estruturar em torno da categoria gênero, a Lei 11.340/06 consagra em seu diploma formas de violências dirigidas, sobretudo, contra as mulheres, fixando um sujeito passivo próprio, o que aparentemente não se estende ao sujeito ativo, que, segundo a interpretação do dispositivo, poderá ser o homem, mas também outra mulher, rompendo com a fixação dualista de gênero (Campos, 2011).

A categoria gênero integra os estudos das Ciências Humanas e Sociais servindo de referencial teórico e analítico, apresentando-se como elemento constitutivo das relações sociais fundadas nas diferenças entre os sexos, também como das relações entre os sujeitos sociais e suas representações de poder (Scott, 1995). Assim, ao adotar o gênero como referencial, a Lei se refere às formas de violência ocorridas entre sujeitos que se inserem desigualmente na estrutura familiar e na sociedade.

Em seus ensaios, a socióloga Heleieth Saffioti já discutia a possibilidade de mulheres perpetrarem violência contra outras mulheres, o que nos dizeres da autora indica que elas estariam exercendo a função de patriarca por delegação (Saffioti, 2001). Estudos 
posteriores apontam para o aspecto relacional das relações conjugais, fugindo ao dualismo vítima e algoz (Gregori, 1989). Estes estudos tiveram importante contribuição para a compreensão da violência contra as mulheres, pois desconstroem a dicotomia entre opressores e oprimidas, revelando a dinamicidade das relações afetivas e elevando a problemática da violência de gênero para uma dimensão que articula o nível intersubjetivo com o estrutural. Levados às últimas consequências, mostram um papel ativo das mulheres no contexto da violência, desafixando sua posição de passividade imutável. É importante salientar que não intentam, de todo modo, responsabilizar as mulheres pelas violências, mas apenas desessencializam as relações violentas, abrindo campo para novas possibilidades protetivas, em que as mulheres continuam sendo as vítimas, porém também são admitidas como autoras de violências.

A partir dos temas apresentados, pertinentes à categoria gênero e às dinâmicas relacionais de poder, salta-nos o entendimento da condição que as

\footnotetext{
${ }^{6}$ Ressalto que não desconsidero o fato de que os homens representam maioria do número de agressores, todavia há um importante grupo de
}

mulheres podem assumir como agressoras dentro de um relacionamento afetivo-conjugal em contexto de lesbianidades, que poderão se dar em desfavor de outras mulheres, e as implicações que este raciocínio nos leva são das mais diversas ${ }^{6}$. Assim, o âmbito de proteção da Lei contemplaria uma importante problematização a respeito das lesbianidades, em que, uma vez evidenciadas as circunstâncias reveladoras de violência fundadas, mormente em razão de gênero, a incidência da Lei Maria da Penha, nestes casos, poderia se dar de forma imperativa, ampliando significativamente o círculo protetivo das próprias mulheres em situações de violências.

Dentre as autoras que teorizaram a respeito das lesbianidades, Gayle Rubin propõe, incialmente, a separação metodológica das categorias gênero e sexo, uma vez que, para a autora, a sexualidade encontra-se regida por mecanismos próprios de opressão sexual que não poderiam ser reduzidos a opressão de gênero, pois assim conduziriam a análises incompletas dos

mulheres que requer a proteção e reconhecimento, especificamente quando a autora de violência for outra mulher. 
fenômenos ligados à sexualidade (Rubin, 1993).Especificamente quanto a categoria sexo, a autora refutou a naturalidade da heterossexualidade, pontuando-a como um produto cultural, já que, no caso do Ocidente, tem-se o sexo como algo destrutivo, perigoso e negativo.

Na concepção de Gayle Rubin, a ideia de binarismo não poderia explicar as variantes das sexualidades humanas, as quais deveriam ser entendidas como um sistema de muitas diferenças que não se esgotam na oposição "hetero-homo". Neste contexto é que a autora pontua privilégios, como reconhecimento, legalidade, mobilidade física e social e apoio institucional, das pessoas que se enquadram ao modelo de sexualidade.

Quanto às lesbianidades, sublinhou em seus estudos o caráter sexual e erótico das relações entre mulheres, discordando da ideia de solidariedade e afeto entre mulheres na definição de lesbianidade ${ }^{7}$, por acreditar que a visão eminentemente romântica da experiência lésbica limita sua complexidade histórica e social, posicionando-se a partir da perspectiva em que as experiências lésbicas inseremse no contexto da sexualidade:

\begin{abstract}
Ao definir o lesbianismo, como um todo, como relações de apoio mútuo entre mulheres, e não como algo com conteúdo sexual, essa abordagem esvaziava - para usar um termo popular - o lesbianismo de qualquer conteúdo sexual. Essa definição tornava difícil distinguir uma lésbica de uma não-lésbica (Rubin e Butler, 2003: 173).
\end{abstract}

Algumas pesquisas (Santos et al., 2014) realizadas abordando a questão da violência e lesbianidades analisam a percepção do público de mulheres sobre a possibilidade de aplicação da Lei Maria da Penha em proteção de mulheres lésbicas que sofrem algum tipo de violência em âmbito familiar e doméstico, em razão de sua orientação sexual. Estas pesquisas apontam para o pouco conhecimento das mulheres, principalmente das heterossexuais, quanto à proteção garantida pela Lei Maria da Penha a casos de violência doméstica em contextos de lesbianidades, alertando para o forte aspecto conjugal-heteronormativo abordado pela publicidade da Lei. De modo que se impede a expansão dos conhecimentos e possibilidades que a legislação oferece ao enfrentamento à

\footnotetext{
${ }^{7}$ A esse respeito, consultar Adrienne Rich.
} 
violência entre lésbicas. Sem dúvida, a chance de casos que envolvam violência lesbofóbica $^{8}$ recaírem no campo de proteção da Lei 11.340/06, acaba por desempenhar fundamental papel no acesso à justiça das mulheres lésbicas, além de ser uma das vias que reconhece legalmente a existência destas relações homossexuais.

Contudo, a discussão acerca das lesbianidades sofreu resistência por parte dos movimentos feministas, sendo esta relação marcada por tensões e aproximações. A agenda feminista, durante muito tempo, deixou de incorporar a questão das lesbianidades no campo de produção teórica e atuação política, o que colaborou para que a experiência lésbica fosse relegada à invisibilidade. Ainda hoje, no Brasil, a violência doméstica contra mulheres lésbicas ou com práticas homoeróticas é pouco documentada, não contando com fonte oficial.

Nesse contexto, a Lei Maria da Penha reúne aspectos convergentes às

8 Lívia Golsalves Toledo, no ensaio "Lesbianidades e biopoder: um olhar genealógico" esclarece que a lesbofobia, como conhecemos hoje, configura-se como uma das formas de homofobia, o que, por sua vez, entende-se como o medo, descrédito, aversão, ódio em direção aos gays, lésbicas, bissexuais, travestis e transexuais ou àquelas pessoas que se presume serem porque não adotam, ou são demandas das variadas vozes dos feminismos, sobretudo ao conter em sua redação expressa menção às questões de orientação sexual e, feita a mais teleológica interpretação, compreende as expressões de violência em contextos de lesbianidades, tirando tais situações de sua condição de invisibilidade e, principalmente, ao abordar as mulheres na posição de agressoras, rompendo com a perspectiva de que a violência seja apenas um comportamento dos homens.

Demonstrado seu papel, a concretização das premissas legais esbarra em problemas atinentes à aplicação da Lei pelo Judiciário. Uma das possíveis razões que contribuem para esses impedimentos estaria no próprio núcleo da Lei, ou seja, a categoria gênero, não antes presente no cotidiano jurídico. Ademais, o Poder Judiciário reúne agentes que estão inseridos em determinado contexto sócio-cultural sendo, no conjunto, produtoras (es) e reprodutoras (es) de uma noção de cultura que, muitas das vezes, reforça os

suspeitas de não adotar, configurações sexuais ditas naturais ou normais. Assim, a lesbofobia pode abarcar procedimentos de exclusão, tanto por meio de discursos ou regimes de verdade sobre as lesbianidades, assim como pela consequente invisibilidade desses sujeitos e as relações que estabelecem relativas a essa forma de existência (Toledo, 2008). 
valores e hierarquias sociais (Hermann e Barsted, 1995).

Apresenta-se necessária a averiguação do modo como os Tribunais tem se apropriado dos preceitos da Lei nos casos envolvendo conflitos entre mulheres, ressaltando-se aqui aqueles ocorridos em relações íntimas de afeto, tanto pelo uso da categoria norteadora do diploma, bem como na constatação de dinâmicas de gênero entre duas mulheres.

\section{O SUL E A LEI MARIA DA}

PENHA:

ANÁLISE

\section{JURISPRUDENCIAL}

A pesquisa jurisprudencial conta, ao todo, com 56 julgados pertinentes a questões envolvendo conflitos entre mulheres nos Tribunais citados. De início, primou-se por decisões que enfocassem o tema das lesbianidades nos conflitos, atendendo ao disposto no parágrafo único do artigo $5^{\circ}$ da Lei. É importante destacar que, neste universo de decisões, havia muitas repetições literais e, inclusive, a apropriação de textos veiculados em outros julgados, o

\footnotetext{
${ }^{9} \mathrm{Na}$ íntegra do voto, os julgadores usaram o termo "homoafetivas" ao se referirem às uniões entre indivíduos do mesmo sexo. Em contrapartida, aqui me utilizo do termo
}

que levou à seleção de apenas alguns decisum, representativos da ideia geral constante nos demais.

Em meio aos resultados jurisprudenciais, elencaram-se os que, de forma simbólica, exprimem e sintetizam a postura de cada Tribunal a respeito da temática violência doméstica e lesbianidades, ou aqueles que permitiram uma reflexão sistemática sobre a postura dos tribunais a respeito da condição das mulheres que agridem outras mulheres.

\section{Caso 01: conflito envolvendo} relacionamento afetivo-conjugal.

Das decisões levantadas, 04 se relacionam a contextos de violência entre ex-companheiras, das quais 02 provém do Tribunal de Justiça do Rio Grande do Sul e 02 do Tribunal de Santa Catarina. A mais expressiva se refere a um julgado proveniente do Tribunal de Justiça do Rio Grande do Sul, versando sobre um conflito ocorrido entre duas mulheres que haviam tido no passado um relacionamento homossexual ${ }^{9}$, estando à época do fato separadas, e em que uma

homossexuais, partilhando da posição adotada por Roger Raupp Rios, que entende que a denominação homoafetividade releva um conteúdo conservador e discriminatório, 
foi denunciada pelas agressões e ameaças cometidas contra sua excompanheira. Consta ainda que a vítima do episódio era continuamente ofendida pela agressora durante o período que as duas estavam juntas, e que por fazer uso de álcool e substâncias entorpecentes, a denunciada demonstrava comportamento violento, dando causa às agressões ${ }^{10}$. Ressalta-se que, durante a fase de investigação, o conflito foi tratado como violência doméstica, e que somente na fase processual pairou dúvida a respeito de seu enquadramento na Lei Maria da Penha.

O relator do caso entendeu pela não incidência da Lei, defendendo que, apesar de o conflito ocorrer durante o período de convivência das envolvidas, o que daria ensejo ao disposto no artigo $5^{\circ}$, inciso III, da Lei, o fato de os sujeitos do conflito serem duas mulheres impediria a aplicação da legislação. Ao que parece, a postura do desembargador vai no sentido de reputar as relações violentas

nutrindo uma lógica assimilacionista, pois, na prática, distinguiria uma condição sexual dita "normal e natural" de outra "assimilável e tolerável", desde que bem comportada e "higienizada" (RIOS, R. R. As uniões homossexuais e a "família homoafetiva": o direito de família como instrumento de adaptação e conservadorismo ou a possibilidade de sua transformação e inovação. Civilista, n. 2, 2013). no âmbito doméstico, apenas e tão somente, para casos que envolvam homens e mulheres, e não duas mulheres. Interessante notar que, na primeira parte de seu voto, o relator elabora o seguinte raciocínio:

[...]Destaco que no parágrafo único do art. $5^{\circ}$ da referida Lei fica bem claro que 'as relações pessoais enunciadas neste artigo independem de orientação sexual', portanto, se aplicam ao caso em apreço, que se trata de duas 'mulheres' envolvidas no episódio, que mantinham um relacionamento homoafetivo. Portanto, uma certeza já emerge desde logo, a pessoa tutelada pela Lei será sempre a mulher, apesar da referência feita pelo parágrafo único do artigo $5^{\circ}$ quanto à orientação sexual.[...](grifo original)

De início, nos leva a acreditar que se posicionaria favorável à aplicação da Lei, contudo, ao final, decide-se pelo seguinte entendimento:

[...]Ainda que o conflito tenha se originado a partir de um período de convivência, o que estaria a caracterizar a violência doméstica, na realidade, o conflito envolve duas mulheres, e portanto não há

${ }^{10}$ BRASIL. Tribunal de Justiça do Rio Grande do Sul. Conflito de competência $\mathrm{n}^{\circ}$ 70036742047, da $3^{\text {a }}$ Câmara Criminal, RS. Relator: Ivan Leomar Bruxel, 06 ago. 2010. Disponível em: http://www.tjrs.jus.br/site/jurisprudencia.

(Acesso em: 28 ago. 2014). 
incidência da Lei Maria da Penha ('11.340/06).[...] (grifo do original)

A argumentação do relator ia em direção do reconhecimento da Lei ao presente caso, porém o desfecho dado é contrário ao raciocínio por ele elaborado, o que demonstrou uma postura contraditória pelo julgador ao analisar o conflito. Por outro lado, os demais desembargadores entenderam, acertadamente, pela incidência da Lei, discordando do relator. Em seus votos, estes julgadores exprimem o entendimento de que a Lei é voltada para a proteção da mulher em situação de violência, não importando o sexo do agressor, que pode ser homem ou mulher, também pontuando que a aplicação da Lei é viável em casos em que a violência doméstica ocorre dentro de relações homossexuais. Exemplificando este entendimento, segue-se trecho do voto de um dos julgadores:

[...]Não importa que a agressora seja outra mulher. A intenção é proteger a mulher nas relações domésticas, afetivas, familiares,

11 Tribunal de Justiça de Santa Catarina. Conflito negativo de jurisdição $n^{\mathbf{o}} 70071791974$, da $6^{\text {a }}$ Câmara Criminal, RS. Relatora: Bernadete Coutinho Friedrich, 09 dez. 2016. Disponível em: http://www.tjrs.jus.br/site/jurisprudencia. (Acesso em: 16 jan. 2017). seja entre homens e mulheres de um mesmo núcleo familiar e, até mesmo mulheres de outra mulheres, embora esta não seja a regra, independente da orientação sexual.[...] (grifo do original)

Tem-se, no presente caso, que o voto do relator foi vencido pelos demais. Ainda, vale ressaltar que a segunda igualmente proveniente do mesmo tribunal $^{11}$ entendeu pela aplicação da Lei em outro caso de violência entre duas excompanheiras.

Nesse contexto, identificou-se, no âmbito da OEA, que no período de pouco mais de um ano (de janeiro de 2013 a março de 2014), praticamente 600 pessoas LGBT foram mortas e outras mais de 170, agredidas de forma grave, sendo que pelo menos 55 destes ataques foram contra mulheres lésbicas. $^{12}$

Sobre a $\begin{gathered}\text { invisibilidade } \\ \text { experienciada nos contextos de }\end{gathered}$
lesbianidades, Maria Célia Orlato Selem
aponta que:

As relações entre mulheres teriam sido silenciadas ou narradas a partir de categorias préestabelecidas, fundando e/ou

12 Agência Patrícia Galvão, "Dossiê violência contra as mulheres: violência contra as mulheres lésbicas, bis e trans". Página consultada a 16.12.2012, em http://www.agenciapatriciagalvao.org.br/dossie/ violencias/violencia-contra-mulheres-lesbicasbis-e-trans/. 
reafirmando discursos totalizantes que norteiam as possibilidades interpretativas do mundo, $[\ldots]$ ou contribuindo para as permanências de poderes e hierarquias (Selem, 2007: 20).

A decisão em questão é um destacado registro da possibilidade de reconstrução desta estrutura, viabilizando condições de liberdade e ampliando o campo de escolha das mulheres em contextos de lesbianidades (Cf. Elias e Machado, 2015).

$$
\text { Com relação as decisões }
$$

advindas do Tribunal de Justiça de Santa Catarina, na primeira se discutia a prática do delito de lesões corporais (artigo 129, caput, do Código Penal), proferidas por uma mulher contra a atual companheira da ex-companheira ${ }^{13}$. O julgado não apresenta outras informações a respeito das possíveis motivações do por que se deram as agressões. Do decisum extraise o seguinte trecho expressivo do entendimento do Tribunal sobre $\mathrm{O}$ conflito:

[...]Ante o exposto, verifica-se no presente caso a não incidência da legislação especial em exame, porquanto, como bem dirimido pelo Juízo suscitante, os autos envolvem uma suposta agressão praticada por uma agente mulher contra uma vítima mulher, não

13 _ Tribunal de Justiça de Santa Catarina. Conflito de jurisdição $\mathrm{n}^{\mathrm{o}}$ 2014.004475-1, $1^{\mathrm{a}}$ Câmara Criminal, SC. Relatora: Marli Mosimann
30

havendo, portanto, uma violência que se originou de uma vulnerabilidade física, uma hipossuficiência financeira $e$ afetiva da agredida em relação à sua agressora[...]. (grifou-se)

Os julgadores, unanimemente, decidem pela não incidência da Lei Maria da Penha. A íntegra do voto ainda contém trechos doutrinários e decisões de outros Tribunais pelos quais o relator ilustra seu entendimento. Nota-se que, em contraste com a decisão anterior, que também versava sobre conflitos ocorridos em relacionamentos lésbicos e em que o Tribunal do estado do Rio Grande do Sul entendeu pela incidência da Lei Maria da Penha, o Tribunal de Santa Catarina pactuou pela sua não aplicação. Pelos critérios utilizados pelos julgadores, a referência feita à vulnerabilidade física nos conduz à ideia de que o sujeito ativo da violência deva ser um homem, e não outra mulher, demarcando bem os estereótipos sociais dos sujeitos, até mesmo por não terem feito reflexão sobre as possibilidades de outras pessoas serem autores (as) das violências.

Vargas, 25 fev. 2014. Disponível em: http://busca.tjsc.jus.br/jurisprudencia. (Acesso em: 29 ago. 2014). 
Já com relação a segunda decisão ${ }^{14}$, proveniente do mesmo, os julgadores entenderam pela incidência da Lei, cujo desfecho do voto do relator apresentou o seguinte argumento:

"Portanto, caracterizado que a ré e vítima conviveram por um determinado tempo e que mantiveram, nesse período, relação íntima de afeto, é indiscutivel que as lesões proferidas por aquela contra esta e que tenham origem em elementos decorrentes do relacionamento pretérito configurem, efetivamente, violência doméstica e familiar a que alude a Lei $n$. 11.340/06". (grifou-se)

O escasso número de julgados versando sobre conflitos entre mulheres em contexto de relação íntima de afeto, em detrimento do restante número de decisões levantadas, reforça a condição de invisibilidade das lesbianidades, notadamente por ser a violência percebida como um problema heterossexual (Nunan, 2004). Pontua-se que não houve menção à categoria lesbianidades no contexto do julgamento. Mesmo assim, o fato de cunhar um precedente favorável ao reconhecimento da incidência da Lei é de

14 Tribunal de Justiça de Santa Catarina. Apelação criminal no 2014.050209-5, $1^{\text {a }}$ Câmara Criminal, SC. Relator: Paulo Roberto Sartorato, 10 mar. 2015. Disponível em: http://busca.tjsc.jus.br/jurisprudencia. (Acesso em: 16 jan. 2017). extrema relevância. A um, porque registra a existência dos relacionamentos afetivos entre mulheres e também a possibilidade de que haja violência nestas relações. A dois, porque confere proteção a estas mulheres. A três, porque a decisão registra a premente discussão sobre a violência contra mulheres lésbicas no país, dentro ou fora do âmbito da Lei Maria da Penha.

Caso 02: conflitos de mãefilha/madrasta-enteada:

Este grupo de análise conta com 27 decisões versando sobre conflitos domésticos envolvendo relação entre mãe e filha e madrasta e enteada. Em um dos julgados, discutia-se um contexto de violência perpetrada pela filha contra a mãe, em que a agressora proferiu ameaças à genitora e depois derrubou-a no chão. No relatório, não constam maiores esclarecimentos sobre possíveis motivações do conflito $^{15}$. O voto do relator, acompanhado pelos demais desembargadores, segue pela não incidência da Lei. Como fundamento de

15 . Tribunal de Justiça do Rio Grande do Sul. Conflito de jurisdição no 70055137608 , RS, da $1^{\circ}$ Câmara Criminal. Relator: Julio Cesar Finger, 19 jul. 2013. Disponível em: http://www.tjrs.jus.br/site/jurisprudencia. (Acesso em: 29 ago. 2014). 
sua decisão, o julgador cita outra decisão do STJ, em que se discute semelhante questão sobre violência envolvendo duas mulheres, do qual se extrai o seguinte trecho:

[...]Delito contra honra, envolvendo irmãs, não configura hipótese de incidência da Lei $\mathrm{n}^{\mathbf{o}}$ 11.340/06, que tem como objeto a mulher numa perspectiva de gênero e em condições de hipossuficiência ou inferioridade física e econômica. 2. Sujeito passivo da violência doméstica, objeto da referida lei, é a mulher. Sujeito ativo pode ser tanto o homem quanto a mulher, desde que fique caracterizado o vínculo de relação doméstica, familiar ou de afetividade. 2. No caso, havendo apenas desavenças e ofensas entre irmãs, não há qualquer motivação de gênero ou situação de vulnerabilidade que caracterize situação de relação íntima que possa causar violência doméstica ou familiar contra a mulher. Não se aplica a Lei $\mathrm{n}^{\circ}$ 11.340/06. 3. Conflito conhecido para declarar competente o Juízo de Direito do Juizado Especial Criminal de Governador Valadares/MG, o suscitado. [...] $]^{16}$ (grifou-se)

Partindo dos critérios apresentados pelos julgadores, saltam dois pontos interessantes por eles apresentados. Em primeiro lugar, pela interpretação feita da Lei 11.340/06 quanto a seus sujeitos, em que reconhecem a mulher como sujeito de

16 Cf. __ Superior Tribunal de Justiça. Conflito de competência $\mathrm{n}^{\mathrm{o}}$ 88027, MG proteção da legislação, bem como a menção à categoria gênero como parâmetro de leitura das situações de violências. De outro lado, alguns parâmetros adotados carecem de precisão teórica e razoabilidade ao causídico em questão, visto que elegem critérios como "condições de hipossuficiência ou inferioridade física e econômica" para motivar a incidência da Lei 11.340/06, entendimento este, aliás, que vem guiando muitas decisões do STJ. Além disso, expressam total confusão entre categorias como sexo e gênero, inferindo, quase que com uma naturalidade equivocada que jamais poderia haver um conflito de gênero entre duas mulheres (Machado, 2014).

De modo geral, a interpretação da Lei ao caso dada pelo Tribunal deu-se de forma acertada ao realizarem leitura do contexto a partir de um parâmetro de gênero e entenderem que o sujeito ativo das violências pode ser tanto homem quanto mulher. Mas, uma importante decorrência deste acórdão e do entendimento partilhado pelos desembargadores, quando se referem à inferioridade física e econômica da vítima, seria a de que uma mulher que 
apresentasse condições econômicas mais favoráveis e equitativas em relação a(o) agressor(a), provavelmente não receberia proteção da Lei, entendimento este que se opõe às próprias disposições da lei, que, sobretudo em seu artigo $2^{\circ}$, destaca que sua aplicabilidade se dá independentemente de classe, raça, etnia, orientação sexual, etc.. Esta perspectiva revela o equívoco que tem permeado as interpretações sobre a incidência da Lei, pautada em critérios de hipossuficiência e vulnerabilidade. Neste sentido, cabe destacar que o próprio fato de estar embasada em uma relação de gênero já confere à relação violenta o critério indissociável da hipossuficiência e da vulnerabilidade, fato este que se sobrepõe a qualquer outra categoria marcadora dos sujeitos, tais quais classe, condição econômica, geração ou raça/etnia, por exemplo.

Caso 03: conflitos entre sogranora:

Grupo com 14 decisões, tratandose de lesões cometidas pela sogra contra nora. Em um deles, o conflito tem início

17 _. Tribunal de Justiça do Rio Grande do Sul. Conflito de jurisdição $\mathrm{n}^{\mathrm{o}} 70054288105$, da $2^{\mathrm{a}}$ Câmara Criminal, RS. Relator: Jaime Piterman, quando a vítima discutia com seu companheiro, por ele não concordar com o término do relacionamento do casal, quando a agressora intervém na discussão e agride sua nora ${ }^{17}$. O relator e os demais julgadores se posicionam favoravelmente à incidência da Lei, inferindo que por ter "motivação de ordem familiar" a questão teria abrigo na Lei 11.340/06.

Ressalta-se que este mesmo Tribunal reconheceu a incidência da Lei Maria da Penha em conflito afetivoconjugal acima analisado. Ademais, o interessante deste caso foi a postura positiva em direção à aplicação da legislação fora de relacionamentos afetivo-conjugais envolvendo mulheres, contemplando as várias esferas domésticas e de convivência dispostas no art. $5^{\circ}$ da Lei. Contudo, ponto curioso foi que se apresentou visível dificuldade de estabelecer o parâmetro gênero fora dos relacionamentos afetivos, uma vez que não houve menção à categoria gênero na decisão.

Quer dizer, a categoria gênero não foi determinante para a incidência da Lei, neste caso, porque não houve uma

30 set. 2013. Disponível em: http://www.tjrs.jus.br/site/jurisprudencia. (Acesso em: 29 ago. 2014). 
articulação entre esta e outros espaços de convívio entre mulheres, fora do âmbito afetivo-conjugal. Foi a dimensão familiar que predominou, ficando registrada a dificuldade dos $\mathrm{r}$. julgadores em admitir que uma relação entre sogra e nora pode, inquestionavelmente, revestir-se de padrões de gênero, ocasionalmente, sobretudo quando esta mesma sogra atua feito representante do próprio cônjuge. De igual modo, fica nítido o entrelaçamento entre a categoria gênero e as relações familiares e o quase automatismo que macula a ideia de que os conflitos de gênero acontecem, necessariamente, no contexto familiar.

\section{Caso 04: conflitos envolvendo} irmãs:

Entre os 03 episódios deste agrupamento, um deles diz respeito a lesões perpetradas por uma mulher contra a irmã, quando esta interveio na tentativa da agressora de lesionar a genitora das envolvidas. Consta no relatório que as ofensas se deram quando a ofendida e sua genitora foram à residência de alguns parentes, local onde

18 _. Tribunal de Justiça do Rio Grande do Sul. Recurso em sentido estrito $\mathrm{n}^{\mathrm{o}} 70057503146$, da $3^{\text {a }}$ Câmara Criminal, RS. Relator: Nereu José a ofensora reside, e que esta tinha problemas psicológicos e histórico de envolvimento com substâncias entorpecentes $^{18}$. O juízo ad quem entendeu pelo não enquadramento do conflito na Lei Maria da Penha, com o argumento de que a violência não era motivada por questão de gênero, é o que se destaca do decisum:

[...]No caso concreto, trata-se de duas mulheres, sendo estas irmãs, e a Lei Maria da Penha se aplica, mormente, quando o sujeito ativo é o homem, uma questão de gênero. [...] (grifou-se)

Neste caso, apesar da tentativa dos julgadores de interpretarem a violência a partir do prisma de gênero, equivocam-se ao estabelecer o homem como único sujeito ativo destes contextos, reforçando uma visão dicotômica sobre a questão da violência doméstica, em que, necessariamente, a agressão deve ser perpetrada pelo homem em direção à mulher, sendo igualmente regida por uma visão heterossexual, desabrigando àquelas mulheres em situações de violências realizadas por outras mulheres, o que reafirma a invisibilidade das violências

Giacomolli, $\quad 10 \quad$ jul. 2014. http://www.tjrs.jus.br/site/jurisprudencia. (Acesso em: 29 ago. 2014). 
decorrentes das relações envolvendo lesbianidades. Sobretudo, inferindo de maneira indireta, que todo tipo de agressão de um homem contra uma mulher será "uma questão de gênero".

\section{Caso 05: conflitos envolvendo} cunhadas:

Este grupo totalizou 04 decisões, sendo que, em uma decisão tendo como episódio levantado no Tribunal de Justiça do Paraná, a denunciada, casada com o irmão da vítima, dividia com esta sua residência no mesmo terreno (andar superior e inferior), tendo ela incorrido nos delitos de ameaça (artigo 147, do Código Penal) e na contravenção de perturbação da tranquilidade (artigo 65, da Lei de Contravenções Penais), como consta na decisão. Isto porque, quando a agressora e seu companheiro se desentendiam, a vítima o abrigava em sua casa $^{19}$. Os julgadores concordaram pela não incidência da Lei 11.340 ao caso. Em seu voto, o relator reitera o posicionamento quanto a questões de submissão financeira:

19 . Tribunal de Justiça do Paraná. Apelação criminal no 1059216-0, Ponta Grossa. Relator: Macedo Pacheco, 23 out. 2013.
[...]Referida lei deve ser aplicada quando se tratar de violência cometida no âmbito das relações domésticas e familiares, contudo, no caso em apreço verifica-se que não há relação íntima de afetividade entre a ré e vítima bem como ausente qualquer relação de submissão financeira ou moral entre elas, o que inviabiliza a aplicação da Lei n ${ }^{\circ}$ 11.340/06. [...] (grifou-se)

Ainda segundo os critérios utilizados pelo julgador:

[...]Com efeito, não é caso de aplicação de Lei Maria da Penha eis que não restou caracterizada relação doméstica ou cometida em âmbito familiar, devendo os autos ser encaminhados ao Juizado Especial Criminal pois conforme consta da denúncia a motivação não se deu em razão do gênero, e sim em decorrência de eventuais desentendimentos entre cunhadas. [...] (grifou-se)

Contudo, a respeito da relação íntima de afeto contemplada pela Lei Maria da Penha, é fundamental revisar o que nos esclarece Pedro Rui da Fontoura Porto:

\footnotetext{
Nesta modalidade dispensa-se tanto a coabitação sob o mesmo teto, quanto o parentesco familiar, sendo suficiente relação íntima de afeto e convivência, presente ou pretérita. A adjetivação "íntima" já pressupõe que se trata de uma relação de caráter sensual, ao menos, inspirada em interesses sexuais, e não simples amizade (Porto, 2007: 25).
}

Disponível em: https://www.tjpr.jus.br/jurisprudencia. (Acesso em: 31 ago. 2014). 
Assim, de pronto se pode verificar uma confusão realizada pelo julgador quando se utiliza dos conceitos de relação íntima de afeto e de relação doméstica ou de âmbito familiar, sendo estas últimas categorias referentes a caráter espacial e vínculo familiar. Sendo tais critérios explorados de forma vaga, está equivocada interpretação realizada pelo julgador também se estende quando ele considera aspectos financeiros como critérios de incidência da Lei, o que nos remete à discussão já realizada quanto às violências ocorridas nas diversas camadas sociais (Oliveira, 2010). É interessante notar como este reducionismo é automático em se tratando de violência doméstica, o que demonstra uma dificuldade de enxergar a violência para além de aspectos financeiros.

Caso 06: conflitos envolvendo primas/tia e sobrinha:

\section{Encontrou-se 01 decisão} envolvendo um episódio de violência entre primas e 01 decisão relativa a conflito entre tia e sobrinha. No primeiro

20 . Tribunal de Justiça do Paraná. Conflito de competência $\mathrm{n}^{\circ}$ 0696069-2, da $1^{\text {o }}$ Câmara Criminal. Relator: Telmo Cherem, 10 caso, o conflito se inicia quando a vítima teria furtado determinado montante em dinheiro da bolsa da agressora, e esta, por sua vez, acusou a vítima de ter praticado a subtração de seus pertences $^{20}$. Os julgadores, por unanimidade, seguiram pela não incidência da Lei, motivado o desicum pelo seguinte posicionamento:

[...] Na espécie, embora presente a relação de parentesco entre os sujeitos ativo e passivo do delito investigado, não se verifica qualquer motivação de gênero ou situação de vulnerabilidade que caracterize hipótese de incidência da chamada Lei Maria da Penha. [...] (grifo do original)

Sem realizar maiores esclarecimentos a respeito dos critérios adotados, reproduzem um julgado do Superior Tribunal de Justiça, trazendo este a discussão a respeito da Lei em conflito envolvendo agressões mútuas entre namorados, motivado pelo ciúme da namorada em relação a seu companheiro. O STJ, por sua vez, entendeu pela não incidência da Lei, fundamentando que o conflito não se funda em questão de gênero, além de discorrer sobre a possibilidade de o

set. 2010. Disponível em: https://www.tjpr.jus.br/jurisprudencia. (Acesso em: 31 ago. 2014). 
sujeito ativo ser homem ou mulher. Ao que parece, apesar de pouco esclarecer a respeito dos critérios utilizados, os julgadores realizam uma correta interpretação da Lei ao caso, pois, pelo exposto no decisum, o conflito não se originou de questões de gênero. Além disto, não se utilizam de parâmetros já discutidos, como hipossuficiência física ou financeira, bem como não mencionam a necessidade de ser o homem como sujeito ativo da violência doméstica, pelo contrário, ao reproduzirem o julgado do STJ, expressaram o entendimento de que a violência pode ser cometida por agressor (a).

No segundo caso $^{21}$, se narra um conflito cuja agressora é a tia da vítima, no qual, diferentemente do envolvendo primas, o Tribunal do Rio Grande do Sul entendeu pela incidência da Lei Maria da Penha, esclarecendo que, apesar de não ser pacífico entre os diversos tribunais brasileiros a respeito do âmbito de incidência da Lei, ela deve ser interpretada de forma ampla, lato sensu, de modo a abranger as relações

21 . Tribunal de Justiça do Rio Grande do Sul. Conflito de competência $\mathrm{n}^{\circ} 70033885385$, da $2^{\text {a }}$ Câmara Criminal, RS. Relatora: Laís Rogéria Alves Barbosa, 25 fev. 2010. http://www.tjrs.jus.br/site/jurisprudencia. (Acesso em: 16 jan. 2017).

22 . Tribunal de Justiça do Paraná. Conflito de competência $n^{\circ} 1389864-1$, da $2^{\circ}$ familiares como um todo e não apenas as que tenham um homem figurando como sujeito ativo. Apesar das discussões sobre a incidência da Lei e a ocorrência de questão de gênero nos dois casos, é interessante observar a forma como cada um dos dois tribunais avaliou 0.

\section{Caso 06: Decisões diversas:}

Por fim, este grupo contém 02 julgados, cujos contextos não se enquadravam nos demais já analisados, mas que igualmente tratava de episódios de violência entre mulheres. Em um deles, oriundo do Tribunal de Justiça do Estado do Paraná 22 é narrado um conflito entre duas mulheres que, contudo, no teor da decisão não consta informação a respeito de vínculo de parentesco ou relação íntima de afeto entre as envolvidas, se limitando os julgadores a decidir pela não incidência da Lei Maria da Penha.

$\mathrm{O}$ outro caso $^{23}$, proveniente do Tribunal de Justiça do Rio Grande do Sul, tem-se um episódio a vítima,

Câmara Criminal. Relator: Luís Carlos Xavier, 17 mar. 2016. Disponível em: https://www.tjpr.jus.br/jurisprudencia. (Acesso em: 16 jan. 2017).

23 __ Tribunal de Justiça do Rio Grande do

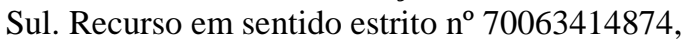
da $3^{\text {a }}$ Câmara Criminal, RS. Relatora: Osnilda Pisa, $\quad 30 \quad$ jul. 2015. 
adolescente, foi ameaçada pela companheira de sua genitora. $\mathrm{O}$ conteúdo da decisão traz relatos da vítima que esclareceu que foi ameaçada pela agressora inclusive em outros episódios envolvendo sua genitora e sua companheira. Entenderam pela incidência da Lei, frisando que o fato de a vítima ser adolescente e a agressora possuir dez anos a mais que a vítima é circunstância que indica a situação de hipossuficiência da primeira.

Conforme se nota, todas estas decisões refletem, de algum modo, o posicionamento mais ou menos favorável às diversas situações de violências contra mulheres, praticadas por outras mulheres. No teor das interpretações conferidas à categoria gênero é que se tem uma maior restrição ou ampliação das garantias e direitos destas mesmas.

\section{CONSIDERAÇÕES FINAIS}

A esfera jurídica é produto de um sistema histórico-cultural, constituindose como um sistema amplo e complexo que, muitas vezes, produz e reproduz determinada noção de cultura que, ao mesmo tempo, ilumina e reforça valores culturais e hierarquias sociais. A partir das análises jurisprudências, percebeu-se um reforço por parte dos Tribunais em reproduzir uma concepção heterossexual de interpretação da violência doméstica, ao aplicar, no contexto de incidência da Lei Maria da Penha, a leitura de supremacia do homem sobre a mulher, demonstrando dificuldade em compreender a mulher como agressora em cenários de violência doméstica, tendo como parâmetro a categoria gênero.

Pelas decisões levantadas, verificou-se dissenso entre os Tribunais sulistas, já que enquanto no estado do Rio Grande do Sul encontraram-se decisões que reconheceram a incidência da Lei em contextos de violência doméstica e lesbianidades, nos demais, além de poucas as decisões envolvendo conflitos entre mulheres e a discussão de aplicação da Lei Maria da Penha, estes tribunais, mormente, inclinaram-se pela sua não aplicação. Ainda, no caso de Santa Catarina, em que foram encontrados dois julgados relativos a contextos de lesbianidades, tendo apenas um deles entendido pela incidência da 
Lei, de modo geral, a pesquisa constatou restrito número de decisões versando sobre conflitos de mulheres e Lei Maria da Penha em comparação aos outros Estados. Os critérios utilizados pelos Tribunais na interpretação dos casos foram dos mais diversos, desde parâmetros de hipossuficiência física e do sujeito ativo figurando como homem, até o próprio disposto no parágrafo único do artigo $5^{\circ}$ da Lei, fazendo direta menção à orientação sexual. De igual modo, foi preciso analisar casos que não se referiam aos contextos de lesbianidades, para nestes obter igual parâmetro de como os tribunais têm estruturado as respostas aos casos de violências envolvendo mulheres.

Foi possível, por fim, constatar uma dificuldade por parte dos (a) julgadores (a) em discutir a condição das mulheres como agressoras, lacuna que incorre em prejuízos para as mulheres que sofrem agressões de outras mulheres, em contextos de lesbianidades, o que vem a recrudescer o quadro lesbofóbico que vivemos atualmente. Bem como nos casos em que se discutiram agressões em relacionamentos afetivo-conjugais lésbicos não se pontuou a categoria lesbianidades, o que, como já discutido, reforça a condição de invisibilidade as violências decorrentes destes relacionamentos.

\section{REFERÊNCIAS BIBLIOGRÁFICAS}

Agência Patrícia Galvão, "Dossiê violência contra as mulheres: violência contra as mulheres lésbicas, bis e trans". Página consultada a 16.12.2012, em http://www.agenciapatriciagalvao.org.br /dossie/violencias/violencia-contramulheres-lesbicas-bis-e-trans/.

Andrade, Vera Regina Pereira (2003), Sistema penal máximo $\mathrm{x}$ cidadania mínima: códigos da violência na era da globalização. Porto Alegre: Livraria do Advogado. [1. ${ }^{\mathrm{a}}$ ed.].

Santos, Tatiana Nascimento dos et al. (2014), "Percepções de mulheres lésbicas e não-lésbicas sobre a possibilidade de aplicação da Lei Maria da Penha em casos de lesbofobia intrafamiliar e doméstica", Revista Bagoas - Estudos gays: gênero e sexualidade 8(11), 101-120. Consultado a 08.04.2016, em https://periodicos.ufrn.br/bagoas/article/ view/6545/5075. 
Avena, Daniella Tebar (2010),

"Violência doméstica nas relações lésbicas: realidades e mitos", Aurora: Revista de Arte, Mídia e Política, 7, 99111. Consultado a 28.11.2014, em http://www.pucsp.br/revistaaurora/ed7 v_janeiro_2010/artigos/download/ed7/5 _artigo.pdf.

Batista, Nilo (2009), "Prefácio", in Mello, Adriana Ramos de (Org.), Comentários à Lei de violência doméstica e familiar contra a mulher, Rio de Janeiro: Lumen Juris. [2. ${ }^{a}$ ed.].

Campos, Carmen Hein (2011), "Razão e sensibilidade: teoria feminista do Direito e Lei Maria da Penha", in Campos, Carmen Hein (Org), Lei Maria da Penha comentada em uma perspectiva jurídicofeminista, Rio de Janeiro: Lumen Juris.

Elias, Maria Lígia Granado; Machado, Isadora Vier (2015), “A construção social da liberdade e a Lei Maria da Penha", Revista Sul-Americana de Ciência Política, 3, 88-109. Consultado a 19.04.2016, em https://periodicos.ufpel.edu.br/ojs2/inde x.php/rsulacp/article/view/3865/4324.
Gabardo, Emerson; Morettini, Felipe Tadeu

Ribeiro

(2013), "Institucionalismo e pesquisa quantitativa como metodologia de análise de decisões judiciais", Revista da Faculdade de Direito da UFMG, 63, 151180. Consultado a 15.07.2014, em http://www.direito.ufmg.br/revista/inde X.php/revista/article/view/P.03042340.2013v63p151.

Gregori, Maria Filomena (1989), “Cenas e queixas: mulheres e relações violentas". Novos Estudos CEBRAP, 23, 163-175. Consultado a 10.08.2014, em http://novosestudos.uol.com.br/v1/files/ uploads/contents/57/20080623_cenas_e queixas.pdf.

Hermann, Jacqueline; Barsted, Leila Linhares (1995), O judiciário e a violência contra a mulher: ordem legal e a (des)ordem familiar, Rio de Janeiro: Cadernos Cepia.

Lei $\mathrm{n}^{\mathrm{o}} 11.340 / 2006$ de 7 de Agosto. Diário Oficial da União de 8.8.2006. Brasília.

Machado, Isadora Vier (2014), “O que diz o TJPR sobre a categoria gênero?: análise jurisprudencial no contexto da 
Lei Maria da Penha”, João Pessoa, Anais eletrônicos do XXIII Congresso Nacional do Conpedi/UFPB. Consultado a $\quad 03.03 .2015, \quad$ em http://publicadireito.com.br/artigos/?cod $=2 \mathrm{a} 2 \mathrm{~d} 16 \mathrm{a} 741 \mathrm{cf} 3 \mathrm{a} 77$.

Nunan, Adriana (2004), "Violência doméstica entre casais homossexuais: o segundo armário?”, PSICO, 35 (1), 6978.

Oliveira, Rosane Teixeira de Siqueira e (2010), "Estatísticas de violência doméstica no Brasil: possibilidades de análise", Florianópolis. Anais eletrônicos do Fazendo Gênero 9. Consultado a 20.08.2014, em http://www.fazendogenero.ufsc.br/9/res ources/anais/1278280957_ARQUIVO_ $\underline{\text { RosaneTeixeiradesiqueiraeOliveira.pdf. }}$

Porto, Pedro Rui Da Fontoura (2007), Violência doméstica e familiar contra a mulher: lei 11.340/06 análise crítica e sistêmica. Porto Alegre: Livraria do Advogado. [3. ${ }^{\mathrm{a}}$ ed.].

Rios, Roger Raupp (2013), “As uniões homossexuais e a "família homoafetiva": o direito de família como instrumento de adaptação e conservadorismo ou a possibilidade de sua transformação e inovação", Civilista, 2, 1-21. Consultado a 13.11.2014, em http://civilistica.com/wpcontent/uploads/2015/02/Rioscivilistica.com-a.2.n.2.2013.pdf.

Rubin, Gayle (1993), “O tráfico de mulheres: notas sobre a "economia política" do sexo", SOS Corpo, 1-32.

Rubin, Gayle; Butler, Judith (2003), "Tráfico sexual: entrevista", Cadernos Pagu, 21, 157-209. Consultado a 03.08.2014, em http://www.scielo.br/scielo.php?script=s ci_arttext\&pid=S0104$\underline{83332003000200008 .}$.

Saffioti, Heleieth (2001), "Contribuições feministas para o estudo da violência de gênero", Cadernos Pagu, 16, 115-136. Consultado a 10.09.2014, em http://www.scielo.br/pdf/cpa/n16/n16a0 7.pdf.

Scott, Joan Wallach (1995), "Gênero: uma categoria útil de análise histórica", Educação e realidade, 20, p. 71-99.

Selem, Maria Célia Orlato (2007), “A liga brasileira de lésbicas: produção de 
sentidos na construção do sujeito político lésbica”, Universidade de Brasília, Tese de Doutorado em História, 195. Consultado em 01.09.2014, em http://repositorio.unb.br/bitstream/1048 2/2397/1/Dissert_MariaCeliaOrlatoSele m.pdf.

Secretaria de Políticas Para Mulheres (2013), "Lei Maria da Penha já gerou mais de 350 mil medidas protetivas e mais de 860 mil procedimentos judiciais". Página consultada a 10.10.2014, em

http://www.spm.gov.br/areaimprensa/ultimas_noticias/2013/09/2709-lei-maria-da-penha-ja-gerou-maisde-350-mil-medidas-protetivas-e-maisde-860-mil-procedimentos-judiciais.

Senado Federal (2012), “CPMI Violência contra a Mulher". Página consultada a 07.11.2014, em http://www.senado.gov.br/atividade/co $\underline{\text { missoes/comissao } \cdot \text { asp? } \text { ?rigem }=\mathrm{CN} \& \mathrm{co}}$ $\mathrm{m}=1580$.

Soares, Gilberta Santos; Sardenberg,

Cecília Maria Bacellar (2011), "Assumindo a lesbianidade no campo teórico feminista", Curitiba, Anais eletrônicos do XV Congresso Brasileiro de Sociologia, 1-17. Consultado a 03.08.2014, em http://www.sbsociologia.com.br/portal/i ndex.php?option $=$ com_docman\&task $=\mathrm{c}$ at_view\&gid=185\&Itemid=171.

Toledo, Lívia Gonsales (2008), "Lesbianidades e biopoder: um olhar genealógico", Revista de psicologia da UNESP, 7, 176-188. Consultado a 10.09.2014, em http://seer.assis.unesp.br/index.php/revp sico/article/view/481. 